\title{
Challenges and obstacles for the first digital repository for tourism studies in Greece
}

\author{
Aristeidis Gkoumas ${ }^{1 *}$
}

Received: 09/02/2017 Accepted: 05/07/2017

\footnotetext{
1 Senior Lecturer, Burapha University International College, International Hospitality and Tourism Management Program, 169 Longhard-Bangsaen Rd, Chonburi 20131, Thailand, Tel.:+66 0649742120; e-mail: aris.gkoumas@gmail.com

* Corresponding author
}

\begin{abstract}
This paper evaluates the visibility, utility, and operability of the first Digital Repository for Tourism Studies in Greece. The creation of the repository was a project that funded and supervised by the Ministry of Tourism, aiming at the collection and analysis of tourism research, conducted from 1980 and onwards. By following a qualitative approach, this study analyzes the challenges and obstacles of developing a digital archive of scientific publications, studies, Ph.D. dissertations and other research data related with tourism in Greece. In particular, it outlines the financial limitations of the project; operational dysfunctions of the online archive; security of the digital content and issues of maintenance, management and technical support of the digital repository in the future. Based on desk review, personal interviews and peer-research working groups, attended by representatives of major tourism institutions, professional organizations and public authorities, the findings of this inquiry indicate that financial and human resources insufficiency, inadequate time frame and lack of promotion, have hindered the success of the project. The paper concludes with specific recommendations for the efficient management and financial sustainability, security of web content and optimal promotion of open access repositories.
\end{abstract}

(C) 2018 Varna University of Management. All rights reserved

Keywords: Digital repository, tourism research, tourism development, Greece, open access content, copyrighting.

Citation: Gkoumas, A. (2018) Challenges and obstacles for the first digital repository for tourism studies in Greece. European Journal of Tourism Research 18, pp. 146-159

\section{Introduction}

Tourism has been served as a vehicle for shoring up the Greek economy against the recent recession, contributing significantly to the national income and reducing unemployment (INSETE, 2017). According to the records of the Greek Statistical Authority and the Bank of Greece, in 2015, the international tourism receipts exceeded the $\$ 14$ billion, while the number of tourism arrivals reached the 24 billion (Bank of Greece, 2016). Also, in 2016 the contribution of travel and tourism to Greek GDP scaled up to $18,6 \%$, while total tourism employment corresponded 
to $23,4 \%$ of the overall workforce (WTTC, 2017).

Taking advantage of the new digital technologies and the explosion of the internet, universities, private and public institutions have established digital repositories and academic libraries in order to collect, preserve and disseminate intellectual and scientific outputs, making research material available online without price or permissions barriers (Wu, 2015; Suber, 2012; Schöpfel, 2017). Building a repository is a cost effective, relatively simple process for providing access to a broad range of research content, increasing the visibility and the availability of scientific information ( $\mathrm{Wu}$, 2015; Schöpfel, 2017). Particularly the Open Access repositories make rich databases of research data and metadata available to interested constituencies in an easy and free manner.

Since 1980s many studies have analyzed extensively the impact of tourism development on the economic, environmental, social and cultural life of Greece. However, the scientific publications, academic studies, books, Ph.D. dissertations, statistical records and other related data on Greek tourism are scattered across the country in institutional libraries, private archives, and databases of universities or research centers, making the accessibility and aggregation of these research assets, extremely difficult.

Filling this gap, the Greek Ministry Tourism in 2015 initiated a project for the development of a National Electronic Repository for Tourism Studies. Although that was among the main priorities of the Ministry for years, still, the absence of a concrete strategy with specific goals for Greek tourism, combined with structural disconformities of public administration and lack of financial recourses, postponed this initiative. Finally, the administration of the Ministry despite several operational hinders and bureaucratic proceed to the implementation of the project.

The ultimate objective of the repository was to create a self-archiving online database of tourism studies carried out in Greece from 1980 and onwards. However, developing an integrated digital repository at a national level, confronted various obstacles. The aim of this paper is to analyze i) the operational restrictions and the financial constraints of the project, ii) the level of online visibility of the digital repository, iii) copyright and authorships issues regarding the content of the online database and iv) the future maintenance and management of the digital repository.

\section{The current landscape of digital repositories}

The explosion of the Internet with the continuous progress in developing web-based materials combined with the new, emerging technologies, increase the effectiveness of processes for managing, searching, retrieving and sharing scientific data and information (Tenopic et al., 2015; Krueger, 2013; Vasileiou, Rowley \& Hartley, 2012). Within this context libraries have shifted rapidly from the offline to online environment by applying appropriate technologies to manage, preserve and share electronic resources and records, offering accessibility to various users without financial, legal, and/or technical barriers (Schöpfel, 2017; IRMT, 2009; Kasprowski, 2008; Kerr, 2010; Olle \& Borrego, 2010; Weir, 2010; Whitfield, 2011). The ongoing transformation of the digital landscape creates cutting-edge technologies and innovations for accessing information online (Wu, 2015). Open access databases and repositories repository are effective tools for sharing scientific information and disseminating research outputs, speeding the transfer of knowledge across scientific disciplines while increasing the collaboration among various researchers (Schöpfel, 2017; Wu, 2015; OECD, 2015)).

The digital repositories are electronic collections and/or archives of outputs and data created by organizations and entities for various purposes. Often online libraries deploy subject-based repositories to collect, preserve and showcase research data, metadata, and intellectual properties. The increasing use of web engines has paved the way for indexing the content of the digital repositories easily and without cost. Google alone accounted for more than $64 \%$ of user traffic in research repositories (Brody et al., 2007). Many digital repositories are of Open Access (OA), while some provide 
access only to subscribed users charging a small admission fee. According to the Registry of Open Access Repositories (ROAR) and the Directory of Open Access Repositories (OpenDOAR), there are more than 4.400 repositories around the world. There are two types of $\mathrm{OA}$ repositories. The first and most common is that of institutional repositories often served as digital platforms for libraries of universities and research centers. The second type is the thematic repository, like the Economics repository (RePEc) or the Physics repository (arXiv) generally open to members of the scientific community.

In the case of tourism the vast majority of digital repositories are institutional, habitually hosted or linked with online libraries of universities and colleges with academic programs affiliated with travel, tourism, leisure, and hospitality. Only handful of them established by tourism organizations at international level, like the UN Digital Repository of Economic Commission for Latin America and the Caribbean (ECLAC) or at a national level, such as the National Portal and Digital Repository for Museums in India. The latter is a very successful example of an open access repository created by a governmental organization like the Indian Ministry for Culture and Tourism. The repository provides an online access to digital content of heritage collections virtual tours, videos and photos of 10 national museums, by using also various sources of social media (e.g YouTube, Facebook).

There are also many national initiatives and transnational/international projects for developing digital repositories for various purposes, such as DRIVER (EU), EUROHORC (EU), DRF (Japan), JISC/RSP (U.K), DAREnet/NARCIS initiative (Netherlands), HAL (France) CARL IR program (Canada) and ProgrammebleWeb (U.S.A). The ultimate objective of those projects was the enhancement of the value and interoperability of individual digital libraries, aiming at the aggregation of digital infrastructure and the development of common services for the end users. Except maybe the DRIVER initiative, which was focused on improving civil society resilience in crisis management, all the other projects dedicated to research and education, addressed basically to students, researchers and faculty members. The benefits of these institutional repositories were: a) Collection and preservation of digital outputs, b) Maximization of the visibility of educational institutions and organizations, c) Opening up the research data, methodologies and case studies to the wider public, and d) Showcasing solutions and sharing digital content with interested groups on a global scale.

However, the main drawback of these initiatives and projects was to cover the recurrent costs necessary for running and managing the repositories in the long run. In general, there is a cash cost for the institutions or organizations to establish and maintain a digital repository bur hardly ever any payoff. Apart from CAPL IR and the JISC programs, which continue to be active, the rest received funding only during the period of their implementation. Institutional repositories require a constant upgrade of software and technical support for the successful operation of their digital platforms and libraries. Without the appropriate financial and human resources, the sustainability of the repositories is highly disputable. A feasible solution to address this problem might be that of the JISC project, which has managed to ensure the financial viability of the repository and provide quality digital services by charging a fee to universities and by applying a membership system for sharing the web content of online libraries.

Some other important issues for Open Access repositories are copyright permissions and authorships of the digital input. Without a basic supervision and evaluation of the web content by an appointed repository manager copyright matters may be occurred. Finally, it seems that the development process of these repositories lacks any communication strategies and/or promotion tools, to inform the wider public or the interested groups about their content or outputs. It is certain that the limited dissemination of information may reduce the visibility and harm the traffic use of the repositories.

\section{Developing a digital repository for tourism studies in Greece}

Institutional Repositories (IRs) are a common tool for collecting and making accessible a 
rapidly growing volume of digital resources. In Greece, although there are several digital libraries of small scale, mainly in Universities and/or research centers, the largest and most advanced institutional repository is that of the National Documentation Centre. The Centre is a public organization that offers an integrated digital environment for accessing databases of research content, as well as a range of services to five digital libraries and seven thematic repositories. By using the European Regional Development Fund (2007-2013) the Centre has developed a "National Information System for Research and Technology" (NISRT). That was a project focused on the creation of a modern platform for various digital repositories with free access to valuable archives of research data and metadata, etheses, e-books, studies, scientific publications, educational material and open software. Even if the National Documentation Centre claims that the repositories are custom-made based on a user-generated content system, in reality, there are documentation regulations and management policy rules for using the digital assets. Furthermore, the Centre charges each institution a fee on a yearly basis for the creation, maintenance, and management of a depository.

Due to these reasons, the Greek Ministry of Tourism decided to develop its own project for the creation of the digital repository without the collaboration of the National Documentation Centre. In the beginning of 2015, the Secretariat of the Ministry subcontracted the University of the Aegean in order to build the first Digital Repository for Tourism Studies from 1980 and onwards. It is believed that during this period the number of research studies, scientific publications, Ph.D. dissertations and statistical data carried out in Greece, regarding tourism management has increased drastically. However, there was no systematic filling of research data or metadata for tourism studies and publications in one national aggregator to support the organization and distribution of digital content. Part of the statistical data and scientific material were stored either in institutional libraries of universities and research centers, like the one of Laboratory for Tourism Studies (ETEM) or in repositories of other organizations, like those of the Greek
Tourism Confederation (SETE), the Hellenic Chamber of Hotels, and the Research Institute for Tourism (ITEP).

Taking into account the current needs, the Ministry of Tourism decided to establish an advanced e-infrastructure for unrestricted, direct and easy online access to digital content of tourism research. The ultimate objective of the project was the creation of the first integrated national digital repository for tourism studies in Greece. The repository will offer free access to an electronic database of research studies, scientific publications, Ph.D. dissertations, statistical reports, data and metadata related to tourism development in Greece. The Ministry envisaged by applying an advanced documentation system and sophisticated digital services to collect, manage and distribute the electronic content of the repository to the scientific, academic, educational and business community of Greece. The project is one of these very few examples of an institutional repository built by a National Tourism Organization (NTO) such as the Ministry of Tourism and it consists of the three following interrelated phases.

\section{(1) Phase A}

This phase referred to the creation of a digital platform and an integrated online archive of tourism studies carried out in Greece from 1980 and onwards. The platform provided free access to scientific publications, studies, Ph.D. dissertations and research data, conducted by various organizations, institutions, and authorities, such as municipalities, ministries, governmental agencies, universities, research centers/laboratories, private companies, consultant agencies etc. The archive followed a chronological order based on the year of publication.

\section{(2) Phase $B$}

Phase $B$ divided into two parts. The first involved the descriptive analysis of each study and the evaluation of their most important conclusions. The second part consisted of drafting a summary of each study, focusing mainly on scientific findings related directly or indirectly to tourism policies in Greece.

\section{(3) Phase C}


Phase C comprised of an evaluation report of the scientific findings and the research topics of the digital content. The report included specific recommendations and suggestions for future studies so that to improve the current tourism policies, upgrade the institutional framework and foster tourism sustainability in Greece.

\section{Methodological framework and data collection}

Previous studies regarding the creation of electronic repositories have based mainly on the quantitative methods of the desk review, Internet searching and direct conducting with authorities and/or organizations with libraries and data sources. However, this research followed by an interpretive and qualitative approach, applied along with the aforementioned techniques, the qualitative tool of peer-research. By using the methods of desk review and participatory peer research the scientific team developed a comprehensive methodological plan for the project. Also, various resources, archives and contact lists of the Laboratory of Tourism Research and Studies (ETEM) were used so that to reassure the successful completion of the project.

The first step of the research plan was the creation of a list of all the potential informants, namely the organizations, authorities, stakeholders and institutions that could possibly publish or carried out studies related

Table 1. Number of studies by organization

\begin{tabular}{lc}
\hline Type of Organization/Entity & $\begin{array}{c}\text { Number of } \\
\text { studies }\end{array}$ \\
\hline Tourism Institutions/Public & 23 \\
Research Centers & 13 \\
Administrative Regions & 64 \\
Regional Units & 325 \\
Municipalities & 41 \\
Development Agencies & 59 \\
Chambers of Commerce & 20 \\
Research Units in Universities & 13 \\
Research Units in Technological & \\
Educational Institutions & 54 \\
Research Companies & 24 \\
Publishing Houses & $\mathbf{6 3 6}$ \\
\hline Total & \\
\hline
\end{tabular}

to Greek tourism development and policy from 1980 and onwards (Table 1). Using the network and contact database of (ETEM) the research team conducted the informants. Subsequently, data collection involved internal and external desk research. The internal desk review consisted of tracking and listing publications, studies and doctoral dissertations from the database of ETEM. The external desk review included the online search for tourism studies in digital libraries of public authorities and educational/research institutions or from private companies and professional organizations.

Following several discussions, the research team agreed to apply the technique of peerresearch working groups for the effective and quick collection of data. Based on personal acquaintances of the faculty members of the University of the Aegean and the extended communication network and affiliations of the researchers of ETEM more than 50 different professional organizations, ministries, regional units, chambers of commerce, local stakeholders, development agencies and other research institutions were approached. The first week of May 2015 a formal letter of invitation was sent by mail to the directors, presidents, chairmen, CEOs or managers of each entity, institution or company, explaining briefly the aim and the objectives of the project. The recipients were asked to participate in the project by completing a brief e-questionnaire, uploading their documents and files on a web platform. Due to poor response rate, a followup e-mail was sent to non-repliers in the first week of June 2015.

The professional and/or personal acquaintance of the research team with people working at several organizations, public authorities, research institutions and private companies was critical for the successful completion of the project. Some informants were graduates of the University of the Aegean or fellow researchers of ETEM invited to participate in the peerresearch working groups. Four meetings of the peer-research working group were conducted between May-June 2015. For a matter of convenience, the meetings hosted in the administration premises of the University of the Aegean in Athens. The meetings lasted for approximately two hours each and they were 
attended by 12 people of eight different entities, namely the Greek Tourism Confederation (SETE), Hellenic Chamber of Hotels, Hellenic Association of Travel \& Tourism Agencies (HATTA), Greek Tourism Organization (EOT), Research Institute for Tourism Research \& Forecasting (ITEP), Institute of Greek Tourism Confederation (INSETE), Greek Tourist Accommodation Enterprises (SETKE) and National Centre for Social Research (EKKE).

The meetings of the peer working group were facilitated by colleagues of the University of the Aegean who acted as moderators. Furthermore, the informants were requested to give their own insights about the functionality, usability, and interactivity of the digital platform. The peer researchers were asked to evaluate the comparative analysis report of the findings of the study. Additionally, during the working meetings, a beta version of the web repository was presented to the participants for comments and observations.

Finally, the research team of ETEM conducted an extensive desk review of online and offline sources for collecting and tracking publications, files, and documents regarding the tourism studies in Greece. Also, it should be mentioned that the technical guidance of the IT department of the University of the Aegean was of crucial importance for the successful completion of the project.

\section{The content of the web platform of the repository}

The research framework and the technical requirements for the project were based on a systematic research of international and national archiving and restoring standards taking into account the limitations, obstacles of collecting and filing electronic information. The online platform of the repository served a dual purpose. Firstly, it provided step-by-step instructions to public and private stakeholders for simple and fast uploading (http://eate.etem.aegean.gr). Secondly, it offered to users easy access to material of the digital library. The landing page of the web platform included a short description of the project and a brief presentation of the role and mission of the Laboratory for Tourism Research \& Studies of the University of the Aegean (ETEM), responsible for the whole endeavor. The web database displayed tools for online searching, based on keywords, title or phrase of each study. Each user should provide a valid e-mail address in order to create an account. An automated no-reply message was sent individually to e-mail addresses, giving instructions for filling out a short electronic registration form (e-form). After completing the necessary fields of the e-form (see Table 2), the user was allowed to submit the digital material in PDF, WORD or PPT format.

The online platform was initially pilot-tested by the research team on a beta version, for eliminated mistakes, failures and/or any technical problems related to uploading records, size limitations of uploading files and digitalization of materials in the database. After a number of corrective actions, the web platform was officially gone viral. The system supported exporting capabilities of automated reports based on web traffic, a number of visits, information regarding the profile and the contact details of the users, allowing personalized assistance to the users (e.g. reminders, guidance etc.).

\section{Study results and discussion}

The following section presents the opinions and analyzes the views of the peer-researchers participated in the working group meetings regarding four different yet interrelated topics. A) Contractual restrictions, such insufficient time and tight budget of the project, B) Lack of promotion and limited dissemination of information regarding the development of the National Repository; low online visibility and poor visit ratio of the web platform, C) Issues of ownership of the online content and copyright permissions and joint authorships and D) Future maintenance, management and technical support of the electronic repository. Table (3) provides a comprehensive presentation of the main challenges and obstacles of the project.

\section{Operational restrictions and financial limitations of the project}

According to the contract between the University of the Aegean and the Ministry of Tourism, the project of developing the National Repository of Tourism Studies and the 
Table 2. Field settings of the electronic registration form

Title of the study

Level of implementation

Description of the study Terms of use

Format of material

Contact details of the organization Working hours
Name of organization

Sponsor/s

Date of completion of study

National

Regional

Peripheral

Municipal

Local

Other

Keywords Summary/Abstract

A number of pages, volumes, sections etc.

Free online access

Limited online access

Lending

Printing copies

Purchase

Reading only through the repository

Accessibility after permission

Not available to the public

Other

Pdf, word, power point.

Address, city, zip code, phone, email, website

Table 3. Main obstacles and challenges of the project

\begin{tabular}{|c|c|c|c|}
\hline $\begin{array}{l}\text { Operational } \\
\text { Constrains }\end{array}$ & Security Concerns & $\begin{array}{c}\text { Maintenance \& Management } \\
\text { Issues }\end{array}$ & Financial Limitations \\
\hline $\begin{array}{l}\text { Poor cyber metrics of } \\
\text { the online platform }\end{array}$ & $\begin{array}{l}\text { Difficulty to get } \\
\text { copyrights for older } \\
\text { studies }\end{array}$ & $\begin{array}{l}\text { Uncertainty for the } \\
\text { continuation of project }\end{array}$ & $\begin{array}{l}\text { No funding for } \\
\text { communication strategy } \\
\text { and promotion actions }\end{array}$ \\
\hline $\begin{array}{l}\text { Low response rate of } \\
\text { uploaded input }\end{array}$ & $\begin{array}{l}\text { Indifference of some } \\
\text { entities to provide co- } \\
\text { authorships for } \\
\text { collaborative research } \\
\text { outputs }\end{array}$ & $\begin{array}{l}\text { No commitment for future } \\
\text { maintenance of the } \\
\text { repository }\end{array}$ & $\begin{array}{l}\text { Inadequate funding for } \\
\text { human resources }\end{array}$ \\
\hline $\begin{array}{l}\text { Limited visibility of } \\
\text { the digital } \\
\text { repository }\end{array}$ & $\begin{array}{l}\text { There was no claimant } \\
\text { of the web library }\end{array}$ & $\begin{array}{l}\text { No proactive actions for } \\
\text { updating the digital services } \\
\text { and the documentation } \\
\text { software of the repository }\end{array}$ & \multirow[t]{3}{*}{$\begin{array}{l}\text { Current budget cut-offs of } \\
\text { the Ministry of Tourism } \\
\text { put at risk the } \\
\text { continuation of the } \\
\text { project in the long run }\end{array}$} \\
\hline $\begin{array}{l}\text { Insufficient time for } \\
\text { tracking down } \\
\text { tourism research } \\
\text { material }\end{array}$ & $\begin{array}{l}\text { Setting no rules for } \\
\text { protecting the } \\
\text { intellectual property } \\
\text { rights of research } \\
\text { material }\end{array}$ & Lack of repository manager & \\
\hline $\begin{array}{l}\text { Political instability in } \\
\text { Greece delayed the } \\
2^{\text {nd }} \text { phase of the } \\
\text { project }\end{array}$ & & $\begin{array}{l}\text { No provision of technical } \\
\text { support after the completion } \\
\text { of the project }\end{array}$ & \\
\hline
\end{tabular}

deliverance of the comparative analysis report should be completed within a period of six months. The research team has dedicated almost three months for data collection and analysis, time which was certainly inadequate for completing the desk review and content acquisition. A large number of studies were kept in different libraries or archives across 
Greece, some in insular and remote areas, making it difficult to find information regarding the title, content or authors of each research. Time was also an issue, which affected negatively the response rate of institutions, organizations, and agencies that invited to participate in the project. Most of the peer researchers estimated that from 1980 and onwards in Greece were conducted more than 450 studies for tourism development and therefore it would be difficult for many agencies to correspond to the project in time and upload their material to the digital library.

Another obstacle for the project was the tight budgeting. The amount allocated for carrying out the research, creating the online platform and covering the compensations of the researchers was limited. From the discussions with peer researchers, it was clear that time and budget limitations hampered the optimization of the online platform. The informants suggested that in six months, which was the period for the data collection, it was not sufficient for collecting a substantial number of tourism studies.

The language of the web platform was also an issue. The representatives of (ITEP), (INSETE), and (EKKE) claimed that there were several reports and studies on Greek tourism written in English. They believed that the content aggregation and the traffic of the digital repository would be increased significantly if the platform were in English also.

It should be mentioned that from the beginning of the project, the scientific coordinator of the University of the Aegean requested for three months extension and additional funding. Unfortunately, the leadership of the Ministry rejected both requests. Also, the political instability in the country in 2015 with two legislative elections held in January and September of the same year affected negatively the completion of the deliverables. Particularly, the elections of January 2015, which by the way coincided with the initiation period of the project, set a new political landscape in Greece, with an impact on the organizational structure and the budget of several ministries.
Many directors and supervisors of various departments of the Ministry of Tourism replaced with members of the party that won the elections. The new General Secretary for Tourism Infrastructures and Investments has raised questions about the overall feasibility of the project and the financial capacity of the Ministry to support this initiative. This attitude has created a certain degree of uncertainty for the research team, jeopardizing temporarily the continuation of the whole project. Finally, after several meetings with the scientific coordinator of the University of the Aegean, where it was discussed the importance and the multiple benefits of the digital repository for tourism studies, the General Secretary was convinced to proceed with the project.

\section{Online visibility and traffic performance of the web platform}

The visibility of repositories on the web via search engines such as Google is crucial for the effectiveness and usability of open access content (Orduña-Malea \& Delgado LópezCózar, 2016). In particular, the repositories in the form of databases facilitating self-archiving documents, information or files uploading, and retrieval process, have become "a key component for open access" techniques (Orduña-Malea \& Delgado López-Cózar, 2016). Most of the electronic repositories are either disciplinary or institutional (Armbruster \& Romary, 2010). Even though there are clear differences regarding the content, aims, functions and objectives, in general, the first type of repository is dedicated to a specific field of study while the latter produced by organizations, institutions, and public authorities (Wu, 2015). The same principle applies for tourism-led repositories with most of them to serve as online libraries of universities or electronic databases of public authorities.

Additionally, the advent of modern information communication technologies (ICT) offer to research repositories significant benefits, such as faster interpretation of scientific results, rigorous and automated evaluation of outcomes, comprehensive research reward practices, while maximizing the easy and simple reuse of scientific data by researchers and scholars (Assante, Candela, Castelli, et al., 2015). However, in the case of Greece, the 
research material regarding tourism development were scattered in archives and collections of traditional (offline) libraries of public organizations and research institutions, with only a few examples of online libraries those of EOT, INSETE and ITEP.

The success of the project depended on largely on the response of authorities, institutions and research centers for uploading tourism studies directly on the online platform. However, the Ministry of Tourism took no communication actions for disseminating information regarding the creation of the electronic repository. As a result, the number of uploads was relatively low, signaling limited visits and online visibility which is vital for digital repositories, relying upon self-archiving processes and open access content (Orduña-Malea \& Delgado LópezCózar, 2016). The concept of online visibility has been used to describe the ability of a search engine optimization (SEO) to focus on a substantial number of keywords, comments, links, and blogs, conversations, appearing on the web in real time and might be helpful to users to find information regarding a topic, service or product. From the discussions with the informants derived that poor publicity and promotion hindered the online visibility of the platform. It is indicative that there was no official announcement for the development of the digital repository on behalf of the Ministry.

There is also a strong connection between the online visibility and the number of visits to the web platform. Although more than 250 organizations, entities, institutions, public authorities and private companies were individually invited to participate to the project by uploading their research material to the repository, unfortunately, by the end of August 2015 , only $38 \%$ of them responded. The peer researchers of the Institute of Greek Tourism Confederation (INSETE), Greek Tourist Accommodation Enterprises (SETKE) and National Centre for Social Research (EKKE) claimed that the limited dissemination of information regarding the project on the web and in social media resulted in poor online visibility, which explains to some extent, the low traffic of the online repository.

The limited number of data entries on the web repository was further mirrored on its cyber 154 metrics performance. Cyber metrics is "the branch of knowledge which employs mathematical and statistical techniques to quantify websites, their components, and concepts; and assesses the impact of cyber age on society" (Sen, 2004, p.117). In fact, cyber metrics provide indicators for analyzing the level of indexing of repositories on search engines, their web visibility and impact (Orduña-Malea \& Delgado López-Cózar, 2016). According to several researchers, open access platforms provide an advantage on total uploads while increasing the number of web visits for a long time (Wang, Liu, Mao, et al., 2015). However, in the case of the national digital repository for tourism studies, cyber metrics has shown that the data aggregation and the visit ratio were relatively low. According to the traffic statistics of the digital library, till the end of 2016 from a total number of 249 visits, only 14 of the users completed the eform and proceeded to upload research material.

\section{Copyright permissions and authorships issues}

The Information Age has generated a fast process of sharing data and resources by providing advanced restoring ways and effective electronic means for digital content accessibility, retrieving and usability. Open access repository has become an essential component for scientific knowledge (Tenopir et al., 2015) whereas it is considered to be an effective and affordable tool for funders, institutions and other stakeholders for data sharing (Houghton \& Swan, 2013). However, there are certain limitations and restrictions regarding the content of digital repositories. Copyright permissions and intellectual property law play a decisive role in open access publishing and digital sharing of scientific output, (OECD, 2015). Yet, the copyright law for open access repositories differs from country to country, whereas intellectual property rights for sharing digital data are unclear (Tenopir et al., 2015; Wu, 2015). Copyright permissions, co-authorships for research studies and ownerships of the digital content of the online database were major challenges for this study.

According to the U.S. Copyright Office ' the online database consists of a compilation of 
digital information comprised of data, details, abstracts, images, maps, music, sound recordings, video, other digitized material, or references to a particular subject or subjects' and it should provide to users two fundamental elements: i) a data set or combination of multiple sets and ii) a program or a system of retrieving information as an entry point or specific data, information or files (Compendium of U.S. Practices, Chapter:1000, p.6). The web platform created for the purposes of the project contained multiple types of copyrightable content including scientific publications, doctoral dissertations, research works, books, analysis reports, and even collective volumes. The authorship varied for the uploading input of the repository, having material of individual authors, joint authors and studies conducted by the third party.

Public authorities, municipalities, regional units and tourism organizations, often outsourced research institutions, universities, development agencies and/or consultant companies to conduct various studies regarding tourism policy, sustainable development, and destination management. Assuring joint authorships and copyright permissions of research carried out for hire or contract was not an easy task. Representatives of the Greek Tourism Confederation (SETE), Hellenic Chamber of Hotels and Hellenic Association of Travel \& Tourism Agencies (HATTA) argued that the process of getting permissions for joint research would not be feasible due to a practical difficulty to conduct all authors, in particular for collective works of local/regional authorities.

In fact, most of the copyrightable content of the online database was either for volumes of joint authors or studies carried out for hire. Unfortunately, the research team could not be able to get the authorships for nearly $7 \%$ of the collective works on the digital platform due to inability to find the contact details of the joint authors.

One of the contractual obligations for the University of the Aegean was the creation and web design of the online platform. According to the compendium of U.S copyright office practices (2014), the contractor of a website is considered the author of the copyrightable content. In this project, though, it was unclear about who would have the ownership of the web content, especially after the completion of the project. Discussing the issue with the peerresearch working group, it was suggested that the ownership of the web content of the digital library along with the copyright should pass on from the University to the Ministry not only for legal transparency but also for the effective use of the electronic repository in the future.

For the time being, University of the Aegean appears as the official 'claimant' of the web platform, meaning the copyright owner of the exclusive rights of the content of the electronic repository. Nevertheless, the claim of the ownership of the copyright in the material of web platform was not entitled by a contractual or implied right to use the content from the hiring party, namely the Ministry of Tourism. Therefore, University should not be claimed as the 'claimant' since there was no valid transfer of the exclusive copyright permissions and ownership licenses of the uploaded material. The lack of explicit clause regarding the ownership of web content, in the current contract agreement, raises legal issues of who could claim the copyright of the digital library, now and in the future.

\section{Future maintenance and management of the electronic repository}

It seems that the continuation of the project is at stake. Due to an unprecedented economic crisis in Greece the Ministry of Tourism will be extremely tight on allocating funds and/or resources for the maintenance, technical support, and supervision of the digital platform. The research team has explained to the working groups that there was no contractual obligation or foresight for the management of the repository in the future. Several informants argued that the lack of management of the online platform after the completion of the project, the inability to update the digital services or keep track on new input could harm the operability and utility of the repository.

The primary goals of the project were to provide free access to reliable scientific data and to facilitate user-generated content related to tourism research in Greece. However, 
without substantial financial and human resources, the management of the repository, the security of the digital content and the overall utility of the online platform for the following years, cannot be met. Security is an important issue for any digital repository, particularly when it aggregates and disseminates a significant volume of scientific content. It is essential for the protection of the research material of the repository to develop a disaster backup system and a data recovery plan. However, the Ministry did not include any specific recommendations to ensure the quality of the web content or the copyrights of research material.

The process of digital curation, that is the selection, preservation, maintenance, collection and archiving of digital assets may add value to an online repository. Several scholars argued that content acquisition and web interactivity of a digital repository requires the constant development of digital curation services and tools (David \& Alayon, 2016). Additionally, user's helpdesk, technical support, and update of digital documentation software are key components for the functionality and operability of the repository, requiring substantial financial and human resources. Unfortunately, the Ministry did not allocate the necessary funds for covering any of these actions.

It is fairly certain that the digital repository for tourism studies is an important tool that may enhance the quality of tourism research and contribute significantly to the accumulation of scientific knowledge and dissemination of research data to country's academic and business community. Furthermore, the evaluation report of the findings of the web content of the repository could play a crucial role in the development of policies and initiatives, which in the long run may increase the competitiveness of tourism products and the quality of services in Greece. To meet these goals constant management, maintenance and technical support of the digital repository are essential. By acknowledging the importance of the whole endeavor and in order to ensure the continuity of the project, the scientific coordinator proposed to the General Secretary of the Ministry of Tourism to renew the contract with the University of the Aegean for two more years. The response to this request was negative as the secretariat claimed financial constraints and budget cut-offs of the Ministry for the period 2016-2017.

\section{Conclusions and future recommendations}

This paper analyzes the challenges and examines the obstacles regarding the development of the first national digital repository for tourism studies in Greece. The creation of the repository was basically a project initiated in 2015 by the Greek Ministry of Tourism, aiming to offer a free access to an integrated online database of tourism studies conducted in Greece from 1980 and onwards. University of the Aegean was the scientific coordinator of the project responsible for the collection of research data and metadata, the establishment of the online platform and the management of the digital repository till the end of 2016.

Building a digital repository was a rather demanding task, facing several practical as well as operational impediments. The overall conclusion of this study is that an open access library requires an adequate operating budget in order to facilitate digital services, purchase software licensing and cover maintenance needs. Until today few studies have addressed financial issues, providing just a rough estimation of the costs for creating and managing a digital repository (Lynch, \& Lippincott, 2005; Rieh et al., 2007). Since most of the open access repositories are free of charge finding substantial funding sources is crucial for their managing and operating sustainability. Financial viability is also important for the operability and the content recruitment of open access repositories. In the case of Digital Repository for Tourism Studies the tight budget hampered data collection and content acquisition.

Another major issue for digital repositories is copyrighting. Copyright law is a decisive factor for disseminating the scientific output of an open access repository, in a manner that protects the intellectual property rights of the authors. The number of tourism studies in Greece has increased radically during the last 10 years. However, the vast majority of these 
studies were kept in archives of public authorities, private organizations, local stakeholders, development agencies and academic institutions across the country, making the process of tracking down and collecting digital content rather difficult. The lack of systematic documentation of scientific material and metadata in digital libraries has reduced the distribution and stewardship of research output. University of the Aegean faced major obstacles to getting copyrights and authorship permissions for several web content, particularly for older studies, whereas several tourism actors demonstrated low confidentiality to share their research data.

Furthermore, this paper points out that an open access repository should use social media as a supplementary promotional tool to increase online visibility and the web traffic. The lack of integrated communication actions and the limited online promotion of the project led to a low online visibility and poor traffic of the electronic platform. Although all the major tourism actors of Greece have invited to participate in the project, few of them have visited the web platform and only $23 \%$ uploaded their studies to the open access database. The main reason for the small number of scientific inputs to the repository was the absence of continuous and comprehensive communication plan of the project. By using web 2.0 technologies the Digital Repository for Tourism Studies could increase its interoperability and interactivity with periodical posting on the major social media, like Facebook and Linkedln, and special announcements in online newsletters of Greek tourism institutions.

During the working group meetings, some peer-researchers have raised questions regarding the feasibility of the whole project in the near future. Due to the ongoing economic crisis in Greece, Ministry of Tourism could not provide the financial and human resources, necessary for the continuation of the project. The Ministry of Tourism could use the European Structural and Investment Funds for the period 2014-2020, in order to cover the operating and maintenance costs of the online platform. It is further suggested that the development of the Digital Repository for
Tourism Studies should be an integral part of a national marketing strategy for Greek tourism based on realistic objectives, and tangible outcomes, a philosophy, which is generally missing from the public administration planning.

The current study provides also specific recommendations for similar initiatives regarding the creation and management of digital repositories. Firstly, the development and application of a backup system of the digital assets are crucial for the operability and the security of online libraries, particularly those with sensitive data such as scientific publications and research databases.

Secondly, updating and improving the documentation system periodically is essential for aggregating and storing the emerging tourism research outputs. A possible solution to cover the operational and management expenses, while offering quality digital services, is to charge subscribers with a small fee for using digital content. Another option for the effective management and the optimal use of the repository in the long run is to subcontracting a public documentation center (e.g. EKT in Greece) or a private not-for-profit company (e.g. JISC in the U.K) in order to create an integrated digital environment, which will provide secure and easy access to scientific data.

Finally, the findings of this study indicate that setting a management policy, using practical elearning tools and creating a video tutorial, along with appointing a depository manager who will constantly organize, monitor and supervise the digital content, are vital for increasing the interoperability and the effectiveness of a self-archiving library.

\section{References}

API University. (2017). ProgrammebleWeb. U.S.A. URL. https://www.programmable web.com/ (Accessed on 24.04.2017)

Armbruster, C., \& Laurent, R. (2010). Comparing repository types-challenges and barriers for subject-based repositories, research repositories, national repository systems and institutional repositories in serving scholarly communication. International Journal of Digital Library Systems 1(4), 61-73. 
Assante, M., Candela, L., Castelli, D., Monghi, P., \& Pagano, P. (2015). Science 2.0 Repositories: Time for a change in Scholarly Communication. The Magazine of Digital Library Research 21, (1/2). URL: http://www.dlib.org/dlib/january15/assante/ 01assante.html (Accessed on 20.02.2017) Atelejevic, I. (2009). Transmodernity: Remaking our (tourism) World? In Tribe, J. (eds.) (2009) Philosophical issues in tourism. Bristol: Channel View, 278-300. Atelejevic I., Pritchard, A., \& Morgan, N. (2007). The critical turn in tourism studies: Innovative research methodologies. Oxford: Elsevier.

Ateljevic, I., Harris, C., Wilson, E., \& Collins, L. (2005). Getting 'entangled': Reflexivity and the 'Critical turn' in tourism studies. Tourism Recreation Research 30(2), 9-21.

Baloglu, S., \& McCleary, K.W. (1999). A model of destination image formation. Annals of Tourism Research 26, 868-897.

Brody, T., Carr, L., Gingras, Y., Hajjem, C., Harnad, S. \& Swan, A. (2007). Incentivizing the Open Access Research Web: $\quad$ Publication-Archiving, DataArchiving and Scientometrics. CTWatch Quarterly 3(3).

Canadian Association of Research Libraries. (2002). CARL Institutional Repositories Project. URL. http://dspace.ucalgary.ca/ handle/1880/360 (Accessed on 22.04. 2017)

David, L., \& Alayon, S. (2016). Digital Curation projects: A study of selected academic and research repositories in the Philippines. Libres 26 (1), 89-98.

Decrop, A. (2004). Trustworthiness in Qualitative Tourism Research. In Phillimore, J., \& Goodson, L. (eds.) (2004) Qualitative Research in Tourism: Ontologies, Epistemologies, and Methodologies New York: Routledge, 156-169.

Decrop, A. (1999). Triangulation in Qualitative Tourism Research. Tourism Management 20(1), 157-161.

Denzin, N.K. (1997). Interpretive Ethnography: Ethnographic Practices for the 21st Century. Thousand Oaks: Sage Publications, Inc.

Denzin, N., \& Lincoln, Y. (1994). Introduction: Entering the field of qualitative research. In Denzin, N., \& Lincoln, Y. (eds.) (1994).
Handbook of qualitative research Thousand Oaks, CA: Sage Publications Inc, 1-18.

Denzin, N., \& Lincoln, Y.S. (1998). Collecting and interpreting qualitative materials. Thousand Oaks, CA: Sage.

Duranti, L., \& Preston, R. (eds.) (2008). International research on permanent authentic records in electronic systems (InterPARES) 2: Experiential, interactive and dynamic records. Padua, Italy: Italian Archives Association.

European Union. (2016). DRIVER project: Driving Innovation in Crisis management for European Resilience. URL. http://driver-project.eu/ (Accessed on 20.04.2017)

Greenstein, D. (2000). Digital libraries and their challenges. Library Trends 49(2), 290303.

Houghton, J., \& Swan, A. (2013). Planting the green seeds for a golden harvest: Comments and clarification on going for gold. The Magazine of Digital Library Research, 19(1/2).

Johare, R. (2007). A global search for universal models of education and training in electronic records management. Malaysian Journal of Library and Information Science 12(1), 1-22.

Joint Information Systems Committee, UK. (2016). Repositories Support Project. URL. https://www.jisc.ac.uk/ (Accessed on 25.04.2017)

INRIA- French National Institute for Computer Science and Applied Mathematics. (2015). The HAL-Inria platform. France. URL. https://www.inria.fr/en/institute/inria-inbrief/inria-awards/2015-prize-winners/thehal-inria-project-team-support-forresearch-and-innovation-award (Accessed on 24.04.2017)

INSETE. (2017). The contribution of Tourism to the Greek economy in 2015. $2^{\text {nd }}$ editionJanuary 2017. SETE Intelligence, Athens, Greece.

Kasprowski, R. (2008). Best practice and standardization initiatives for managing electronic resources. Bulletin of the American Society for Information Science and Technology 35(1), 13-19.

Kerr, S.H. (2010). Electronic resource management systems. The promise and 
disappointment. Technical Services Quarterly 27(3), 297-300.

Lynch, C.A., \& Lippincott, J.K. (2005). Institutional repository deployment in the United States as of early 2005. The Magazine of Digital Library Research 11(9). URL. http://dx.doi.org/10.1045/ september2005-lynch (Accessed on 01.06.2017)

Ministry for Culture \& Tourism, India. (2014). National Portal and Digital Repository for Museums of India project. URL.http://www.digitalmeetsculture.net/art icle/national-portal-and-digital-repositoryfor-museums-of-india/ (Accessed on 24.04.2017)

National Academic Research and Collaborations Information System (NARCIS). (2007). Digital Academic Repositories Initiative (DAREnet). Netherlands. URL. http://www.narcis.nl./ (Accessed on 26.04.2017)

National Information System for Research and Technology (NISRT). (2001) National Documentation Center of Greece. URL: http: //www.epset.gr/en/Digital-Content/ DigitalRepositories. (Accessed on 22.04.17).

OECD. (2015). Making Open Science a Reality. OECD Science, technology and Industry Policy Papers, (25), OECD Publishing, Paris. URL. http://dx.doi.org/ 10.1787/5jrs2f963zs1-en (Accessed on 31.05.2017).

Ollé, C., \& Borrego, A. (2010). A qualitative study of the impact of electronic journals on scholarly information behavior. Library and Information Science Research (32), 221-228.

Orduña-Malea, E., \& Delgado, López-Cózar., E. (2016). The dark side of the open Access in Google and Google Scholar: the case of Latin-American repositories. Scientometrics. (forthcoming)

Rieh, S.Y., Markey, K., St. Jean, B., Yakel, E., \& Kim, J. (2007). Census of institutional repositories in the U.S.: A comparison across institutions at different states of IR development. The Magazine of Digital Library Research 13 (11/12). URL: http://dx.doi.org/10.1045/november2007rieh (Accessed on 01.06.2017)

Sen, B.K. (2004). Cybermetrics-Meaning, definition, scope and constituents. Annals of Library and Information Studies 51(3), 116-120.

Schöpfel, J. (2017). Open Access to Scientific Information in Emerging Countries. The Magazine of Digital Library Research 23, (3/4). URL: https://doi.org/10.1045/march 2017-schopfel (Accessed on 01.06.2017).

Suber, P. (2012). Open access. The MIT Press, Cambridge MA.

Tenopir, C., Dalton, E.D., Allard, S., Frame, M., Pjesivac, I., Birch, B., Pollock, D., \& Dorsett, K. (2015). Changes in data sharing and data reuse practices and perceptions among scientists worldwide. PLoS ONE 10(8): e0134826. https://doi.org/10.1371/journal.pone.01348 26 (Accessed on 31.05.2017)

Tribe, J. (2004). Knowing about tourism: Epistemological issues. In Phillimore, J., \& Goodson, L. (eds.) (2004). Qualitative research in tourism: Ontologies, epistemologies, and methodologies. London: Routledge, 46-62.

United States Copyright Office. (2014). Compendium of U.S Copyright Office Practices-Third Edition. Chapter 1000: Websites and Website Content. Washington, D.C: U.S.A.

Vasileiou, M., Rowley, J., \& Hartley, R. (2012). The e-book management framework: The management of e-books in academic libraries and its challenges. Library \& Information Science Research 34(4), 282-291.

Wang, X., Liu, C., Mao, W., \&Fang, Z. (2015). The open access advantage considering citation, article usage and social media attention. Scientometrics, 103(2), 555564.

Weir, R. (2010). Electronic resource management systems and the small to medium university library. An argument for implementation. Against the Grain 22(2), 22-24.

World Travel \& Tourism Council, (2017). Country Reports: Travel and tourism economic impact 2017- Greece. London: WTTC.

Wu, M. (2015). The future of institutional repositories at small academic institutions: Analysis and Insights. The Magazine of Digital Library Research 21, (9/10) URL: http:www.dlib.org/dlib/september15/wu/09 wu.html (Accessed on 20.02.2017) 